\title{
Psychometric properties of the kidney disease quality of life-36 (KDQOL-36) in Ethiopian patients undergoing hemodialysis
}

Mignote Hailu Gebrie ${ }^{1 *}$ (D) Hussen Mekonnen Asfaw ${ }^{2}$, Workagegnehu Hailu Bilchut ${ }^{3}$, Helena Lindgren ${ }^{4}$ and Lena Wettergren ${ }^{4,5}$

\begin{abstract}
Background: Health-related quality of life (HRQOL) has a direct association with increased morbidity and mortality among end stage renal disease patients. Valid and reliable instruments to measure the HRQOL of patients with end stage renal disease are therefore required. This study aimed to translate, culturally adapt and evaluate the psychometric properties of the Amharic version of the Kidney Disease Quality of Life-36 (KDQOL-36) instrument in Ethiopian patients with end stage renal disease undergoing hemodialysis.
\end{abstract}

Methods: The KDQOL-36 instrument was developed for individuals with kidney disease who are being treated with dialysis and includes both generic and disease-specific components. The KDQOL-36 was translated to Amharic language and distributed to a cross-sectional sample of 292 hemodialysis patients. The psychometric evaluation included construct validity through corrected item-total correlation, confirmatory factor analysis and known group analysis. Convergent validity was evaluated by correlations between each of the three kidney disease targeted scales (symptoms/problems list, burden of kidney disease and effects of kidney diseases) and the European Quality of Life 5D-5L and Visual Analog Scales. Regarding reliability, internal consistency and test-retest reliability were assessed.

Results: Two hundred ninety-two patients with a mean age of 48 (SD \pm 14.7 ) completed the questionnaire. Corrected item- total correlation scores were $>0.4$ for all items. Confirmatory factor analysis revealed a two $x^{2} / \mathrm{df}$ was 4.4 , Root Mean Square Error of Approximation (RMSEA) $=0.108$ (90\% Cl 0.064-0.095), Comparative Fit Index (CFI) =0.922, Tucker Lewis Index $(\mathrm{TLI})=0.948$ and Standardized Root mean-squared residual (SRMR) $=0.058)$ and three $x^{2} / \mathrm{df}=3.1$, RMSEA $=0.085(90 \% \mathrm{Cl} 0.064-0.095), \mathrm{CFI}=0.854, \mathrm{TLI}=0.838$ and $\mathrm{SRMR}=0.067)$ factor models for the generic and disease specific components respectively. The mean scores of the three kidney disease targeted domains were correlated to the EQ-5D-5L \& VAS with correlation coefficients of large magnitude (0.55-0.81). The reliability of the instrument was satisfactory (Cronbach's alpha $=0.81-0.91$ ) and Intra-class correlation $(I C C)=0.90-0.96)$.

Conclusion: The Amharic version of the KDQOL-36 is a reliable and valid instrument recommended for assessment of HRQOL of Ethiopian patients on hemodialysis.

Keywords: Confirmatory factor analysis, End stage renal disease, KDQOL-36, Quality of life, Reliability, Validity, Hemodialysis, Ethiopia

*Correspondence: elatman.hailu86@gmail.com

${ }^{1}$ College of Medicine and Health Sciences, School of Nursing, University of Gondar, Gondar, Ethiopia

Full list of author information is available at the end of the article

\section{Background}

End stage renal disease (ESRD) is a public health problem resulting in high morbidity and mortality worldwide [1-4]. Globally in 2017, chronic kidney disease (CKD) original author(s) and the source, provide a link to the Creative Commons licence, and indicate if changes were made. The images or other third party material in this article are included in the article's Creative Commons licence, unless indicated otherwise in a credit line to the material. If material is not included in the article's Creative Commons licence and your intended use is not permitted by statutory regulation or exceeds the permitted use, you will need to obtain permission directly from the copyright holder. To view a copy of this licence, visit http://creativecommons.org/licenses/by/4.0/. The Creative Commons Public Domain Dedication waiver (http://creativeco mmons.org/publicdomain/zero/1.0/) applies to the data made available in this article, unless otherwise stated in a credit line to the data. 
resulted in 1.2 million deaths, more than did tuberculosis or Human Immunodeficiency Virus (HIV) [5]. It is the terminal phase of CKD, where the kidneys experience complete or near complete failure and renal replacement therapy is needed to sustain life [6-8].

The worldwide prevalence of ESRD ranges from 2447 cases patients per million population (pmp) in Taiwan to 10 cases pmp in Nigeria. Much less is known in all of Africa, due to lack of renal registry, with the highest prevalence of ESRD in Tunisia (713 pmp) and Egypt (669 pmp). However, it is predicted that the low-income countries of Asia and Africa will be where more than 70\% of patients with ESRD will live by the year 2030 [9]. In Ethiopia, the incidence of CKD is increasing as a result of increasing prevalence of CKD risk factors such as hypertension and diabetes mellitus [10].

Hemodialysis is one of the treatment methods, contributing to increased survival in patients with $\operatorname{ESRD}[11,12]$. However, patients with hemodialysis suffer from a multitude of problems including sleep disorders, peripheral neuropathy, infection, fatigue, stress, anxiety, depression, cognitive difficulties pain and sexual dysfunction [1315]. Hence, assessing the health-quality of life (HRQOL) of ESRD patients is essential as it is an independent predictor of patient's treatment outcome.

Several instruments have been developed to measure HRQOL in ESRD patients [16-18]. The kidney disease quality of life (KDQOL-36) survey is a disease-specific measure of HRQOL including both generic and diseasespecific components. The KDQOL-36 contains 5 subscales and is one of the most commonly used measures for assessment of patients with kidney disease $[16,19]$. The instrument has been translated and validated in various languages [20-23], however, to date its psychometric properties have not been confirmed in an Ethiopia population. Therefore, the objective of this study was to translate, culturally adapt and evaluate the psychometric properties of the KDQOL-36 questionnaire when used among Ethiopian patients with ESRD undergoing hemodialysis.

\section{Methods}

\section{The KDQOL-36 instrument}

The KDQOL-36 was derived from the original 134item KDQOL instrument [24]. The KDQOL-36 version includes the Medical Outcomes Study's 12-Item ShortForm Health Survey (SF-12) as a generic core and the 24-item kidney disease targeted questionnaire [25, 26]. The items of the SF-12 are summarized into the Physical Component Summary (PCS) score and the Mental Component Summary (MCS) with response alternatives varying from 2- to 6-point scales [27, 28]. The kidney disease targeted instrument includes three scales: Symptoms and Problems (12 items), Burden of Kidney Disease (4 items), and Effects of Kidney Disease (8 items); all items have 5 response options. The scale scores of the KDQOL36 questionnaire (PCS, MCS, symptoms and problems, burden of kidney disease, effects of kidney disease,) are transformed to 0 to 100 with higher scores indicating better HRQOL $[24,29]$. We used the KDQOL ${ }^{\mathrm{Tm}}-36$ scoring program (V 2.0) from the University of California, Los Angeles (UCLA) to compute the scale scores. This program is available free for download online (http:// www.rand.org/health/surveys_tools/kdqol.html).

\section{Translation of the KDQOL-36 into amharic language}

The KDQOL-36 was translated from English into Amharic by two professional translators (native Amharic speakers with fluency in English). The translators had a Master's degree in English Language and Literature. The translated Amharic versions were then reviewed by a committee of experts including the investigators, the original translators, nurses working in a hemodialysis unit, a nephrologist and experts in instrument development and translation. Some minor changes were made before the items were translated back into English by two other independent professional translators and were then compared to the original instrument. There were repeated back translations for some items for which deviations were encountered until matching was seen to be sufficiently good to ensure that the Amharic version did not differ from the original instrument. Finally, cognitive testing was conducted on 10 ESRD patients undergoing hemodialysis to determine its cultural appropriateness and acceptability including instructions, items and response choices [29] which resulted in rewording a few items. Translation of the English KDQOL-36 to Amharic was performed according to the basic guidelines for translating surveys (see https://www.rand.org/healthcare/surveys_tools/about_translations.html).

\section{Sample and settings}

A cross-sectional study was conducted at two governments (Menelik II and Zewditu memorial) and six private (Ethio-tebib, Hallelujah, Hayat, Bethel, MABD and Flow) hospitals/dialysis centers situated in Addis Ababa, Ethiopia. Data for the psychometric evaluation were collected over a period of one month, January to February 2021, from patients receiving outpatient maintenance hemodialysis. All patients who fulfilled the inclusion criteria (ESRD patients aged $\geq 18$ years, maintained on regular hemodialysis treatment for $\geq 3$ months and speaking Amharic) were approached regarding possible participation in the study. Hemodialysis patients who provided their consent were then interviewed by trained research assistants and their medical records were consulted to 
obtain clinical data. Participants were asked to respond to study-specific and standardized items (KDQOL$36)$. Two weeks later, a subsample $(\mathrm{n}=50)$ was asked to respond to the Amharic KDQOL-36 again to assess the test-retest reliability.

\section{Additional measures}

In addition to the KDQOL-36, participants were asked to complete the Amharic European Quality of Life 5D-5L and Visual Analog Scale (EQ-VAS) [30]. The EQ-5D-5L is a generic instrument, developed by the European quality of life (EuroQol) Group consisting of five dimensions: mobility, self-care, usual activities, pain/discomfort, and anxiety/depression and an EQ-VAS with a 5-point Likert scale (no problems, slight, moderate, severe, extreme/ unable). The EQ-VAS is numbered from 0 to 100 , where 0 indicated the worst imaginable health and 100 was best imaginable health [31]. Scores were converted to 0 to $100 \%$.

\section{Statistical analysis}

STATA version 14 was used for statistical analysis [32]. Normality was assessed for the outcome variables using the Shapiro Wilk test. Patients' demographic and clinical characteristics were summarized using descriptive statistics (percentages, frequencies, means, standard deviations). Descriptive statistics for the five separate domains of the KDQOL-36 were calculated with means and standard deviation [29].

\section{Data quality}

Data quality was assessed by examination of missing values for each item of the KDQOL-36. Furthermore, we evaluated whether all response alternatives were used for all items as well as floor and ceiling effects. Ceiling effect was measured by the proportion of people rating the highest possible score while floor effects were measured by the proportion of people rating the lowest possible score. These effects were considered significant if $>15 \%$ of the patients scored the lower/higher values [32].

\section{Construct validity}

Construct validity of KDQOL-36 was assessed by using corrected item scale correlation using cut-off scores $\geq 0.4$ to indicate adequate correlation [33]. Confirmatory factor analysis (CFA) was employed to test the model fit between the observed and the hypothetical measures. CFA is a method of choice when the researcher has prior knowledge of the basic latent variable construction [34]. The SF-12 and the kidney disease targeted questionnaire were analyzed separately because they are different questionnaires each having their own unique contribution to the assessment of HRQOL. The validity of SF-12 health survey would be supported if the hypothesized physical and mental component summary scales were identified [27]. CFA would support the disease-targeted part if a three-factor structure was achieved [29]. Model fit was assessed using normed Chi-Square $\left(\chi^{2} / \mathrm{df}\right)$, Root Mean Square Error of Approximation (RMSEA), Comparative Fit Index (CFI), Tucker Lewis index (TLI) and Standardized Root mean-squared residual (SRMR). Normed Chi-Square should be $0-2$ for good fit and $\leq 3$ for an acceptable fit. Values between 0.05 and 0.08 suggest reasonable RMSEA and lower values represent better fit [35]. CFI \& TLI $>0.9$ indicate good fit and that SRMR should be $<1.0$ to consider the model is favorable [36]. We used Maximum likelihood estimation (MLE) [34].

Convergent validity was evaluated by correlation coefficients between the three kidney disease targeted scales with the EQ-5D-5L and EQ-VAS. Pearson's correlation coefficient was calculated where values $0.10-0.29$, $0.30-0.49$ and $>0.49$ represents small, moderate and large magnitude, respectively [37]. It was hypothesized that the three kidney disease specific domains would have moderate to large coefficients with the ED-5D-5L and VAS, respectively.

Known group analyses were conducted to test how well the questionnaire discriminates between subgroups of the study sample that differed in diabetes status, examining a hypothesis supported by previous research [38, 39]. It was expected that patients without diabetes would have better HRQOL than diabetic patients. Independent $\mathrm{t}$-tests and an analysis of variance (ANOVA) were used to evaluate the differences.

\section{Reliability}

Reliability included internal consistency as well as testretest. Internal consistency was estimated using Cronbach alpha coefficient for the different domains of the instrument. Cronbach's alpha between $0.70-0.90$ is suggested to reflect adequate internal consistency [40]. Intra-class correlation coefficient (ICC) was computed to assess test-retest reliability where values $>0.9,0.75-0.90$, $0.5-0.75$ and $<0.5$ indicates excellent, good, moderate and poor reliability respectively [41].

\section{Results}

\section{Socio-demographic characteristics}

The total sample included 292 patients (response rate $96 \%$ ) on maintenance hemodialysis with a mean age 48 $(\mathrm{SD} \pm 14.7)$, please see Table 1.

\section{Data quality}

There were no missing data. All response alternatives were used for all items. Descriptive statistics including floor and ceiling effects are shown in Table 2. 
Table 1 Socio-demographic characteristics of patients with ESRD undergoing hemodialysis in Addis Ababa, Ethiopia, 2021 ( $\mathrm{n}=292$ )

\begin{tabular}{|c|c|c|c|}
\hline Variables & Category & Numbers (n) & Percent (\%) \\
\hline \multirow[t]{2}{*}{ Sex } & Male & 187 & 64 \\
\hline & Female & 105 & 36 \\
\hline Age (years), M (SD) & $48(S D \pm 14.7)$ & & \\
\hline \multirow[t]{2}{*}{ Residence } & In Addis Ababa & 250 & 85.6 \\
\hline & Outside Addis Ababa & 42 & 14.4 \\
\hline \multirow[t]{2}{*}{ Marital status } & Ever married & 232 & 79.5 \\
\hline & Single & 60 & 20.5 \\
\hline \multirow[t]{7}{*}{ Educational status } & Not read and write & 26 & 8.9 \\
\hline & Read and write & 29 & 9.9 \\
\hline & Primary (1-8) & 33 & 11.3 \\
\hline & Secondary (9-10) & 32 & 11.0 \\
\hline & Preparatory (11-12) & 52 & 17.8 \\
\hline & Vocational & 10 & 3.4 \\
\hline & Diploma and above & 110 & 37.7 \\
\hline \multirow[t]{2}{*}{ Occupation } & Employed & 152 & 52.1 \\
\hline & Unemployed & 140 & 47.9 \\
\hline \multirow[t]{3}{*}{ Hemodialysis session per week } & 1 times & 15 & 5.1 \\
\hline & 2 times & 125 & 42.8 \\
\hline & 3 times & 152 & 52.1 \\
\hline \multirow[t]{2}{*}{ Funding } & Yes & 70 & 24 \\
\hline & No & 222 & 76 \\
\hline \multirow[t]{2}{*}{ Family history } & Yes & 11 & 3.8 \\
\hline & No & 281 & 96.2 \\
\hline Duration since start of hemodialysis, M (SD) & 2.4 years $(S D \pm 2.1)$ & & \\
\hline \multirow[t]{4}{*}{ Vascular access type } & Arteriovenous fistula & 218 & 74.7 \\
\hline & Arteriovenous graft & 30 & 10.3 \\
\hline & Permanent catheter & 31 & 10.6 \\
\hline & Temporary catheter & 13 & 4.5 \\
\hline
\end{tabular}

$M$ mean; SD standard deviation

Table 2 Descriptive statistics for the KDQOL-36 questionnaire among hemodialysis patients in Addis Ababa, Ethiopia, 2021 ( $n=292$ )

\begin{tabular}{|c|c|c|c|c|c|}
\hline Domains & No. of items & Mean (SD) & Range of items mean (SD) & $\begin{array}{l}\text { Floor/ceiling } \\
\text { effects, \% }\end{array}$ & Cronbach's alpha \\
\hline \multicolumn{6}{|c|}{ Kidney disease targeted scales } \\
\hline Symptoms/problems list & 12 & $68.19(19.52)$ & $57.10-76.28(24.5-29.8)$ & $0 / 1.0$ & 0.907 \\
\hline Effects of kidney disease & 8 & $57.13(18.28)$ & 39.29-66.44(22.1-30.9) & 0/0 & 0.827 \\
\hline Burden of kidney disease & 4 & $35.57(29.82)$ & 25.43-44.35(30.9-38.6) & $10.6 / 2.7$ & 0.899 \\
\hline \multicolumn{6}{|l|}{ 12-item health survey (SF-12) } \\
\hline SF-12 PCS & 6 & $35.59(8.80)$ & $24.32-43.49(29.8-47.1)$ & 0/0 & 0.813 \\
\hline SF-12 MCS & 6 & $38.85(13.63)$ & $38.56-47.05(28.6-47.1)$ & $0 / 0$ & 0.892 \\
\hline
\end{tabular}

\section{Construct validity}

The corrected item-total correlation coefficients for all items were between 0.41 to 0.85 (data not shown), thus showing adequate correlation. The CFA results for SF-12 showed that $\chi^{2} / \mathrm{df}$ was 4.4 , RMSEA $=0.108$ (90\% CI 0.064-0.095), CFI $=0.922, \mathrm{TLI}=0.948$ and $\mathrm{SRMR}=0.058$ (Fig. 1). Since the RMSEA was relatively high, we re-specified the model (supplementary file 1). The model outputs were similar and as the uncorrected model fitted well with the originally hypothesized two-factor model which forms the basis of the PCS and MCS this was selected. Similarly, in the kidney disease related scales (symptoms/ problems, effects and burden), the data fitted with the hypothetical 


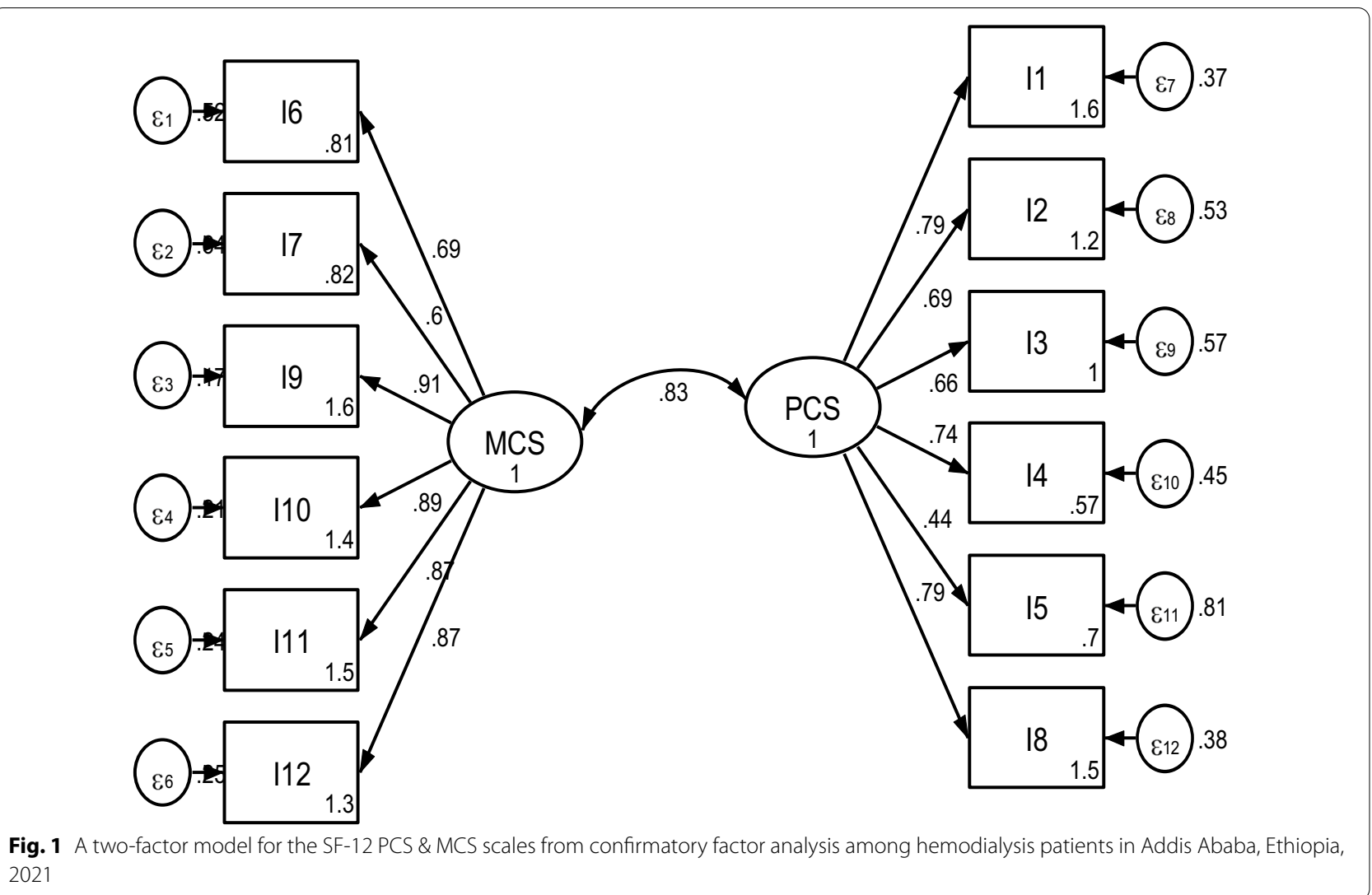

three factor model with $\chi^{2} / \mathrm{df}=3.1, \mathrm{RMSEA}=0.085$ (90\% CI 0.064-0.095), CFI $=0.854, \mathrm{TLI}=0.838$ and SRMR $=0.067$ ) (Fig. 2). Model re-specification was considered since the RMSEA \& SRMR were a bit high and the CFI \& TLI were a bit low. Even though some variability was found that the data couldn't explain, the results were very close to the uncorrected model (supplementary file 2), and we decided to use the uncorrected one. Thus, the kidney disease targeted parts of the KDQOL-36 instrument was revealed as a three factor model as it was hypothesized. The factor loadings of all items in both parts (SF-12 and diseases specific) were positive and exceeded the threshold of 0.4 , which indicates considerable interpretability of original factor structure.

The associations between the three kidney-disease specific domains and the EQ-5D-5L and the EQ-VAS are presented in Table 3. Moderate to strong correlations were evidenced between KDQOL sub scales and the EQ-5D-5L as well as the sub scales and VAS.

Regarding known group validity, patients with diabetes had significantly lower scores for the effects of kidney disease, SF-12 PCS and SF-12 MCS scales (Table 4).

\section{Reliability}

Cronbach's alpha values for the five subscales exceeded 0.80 (Table 2). With regard to test-retest reliability, the subscales had an ICC value ranging between 0.90 to 0.96 (data not shown).

\section{Discussion}

In this study, we evaluated the psychometric properties of the translated and culturally adapted Amharic version of KDQOL-36. Our results indicate that the Amharic version of the KDQOL-36 with the given response alternatives is satisfactory for use among patients who understand the Amharic language. Furthermore, the floor and ceiling effects of the Amharic version of the KDQOL-36 instrument were minimal which is in line with an American study [42]. However, it contrasts with findings from another study in the USA which found a significant floor effect in the 'burden of kidney disease' and 'effects of kidney disease' subscales [22]. The difference in findings could be explained by the reason why psychometric testing of self-report measures is required for use in different languages and on patients from different cultural backgrounds [43]. The minimal floor/ceiling effects indicate 


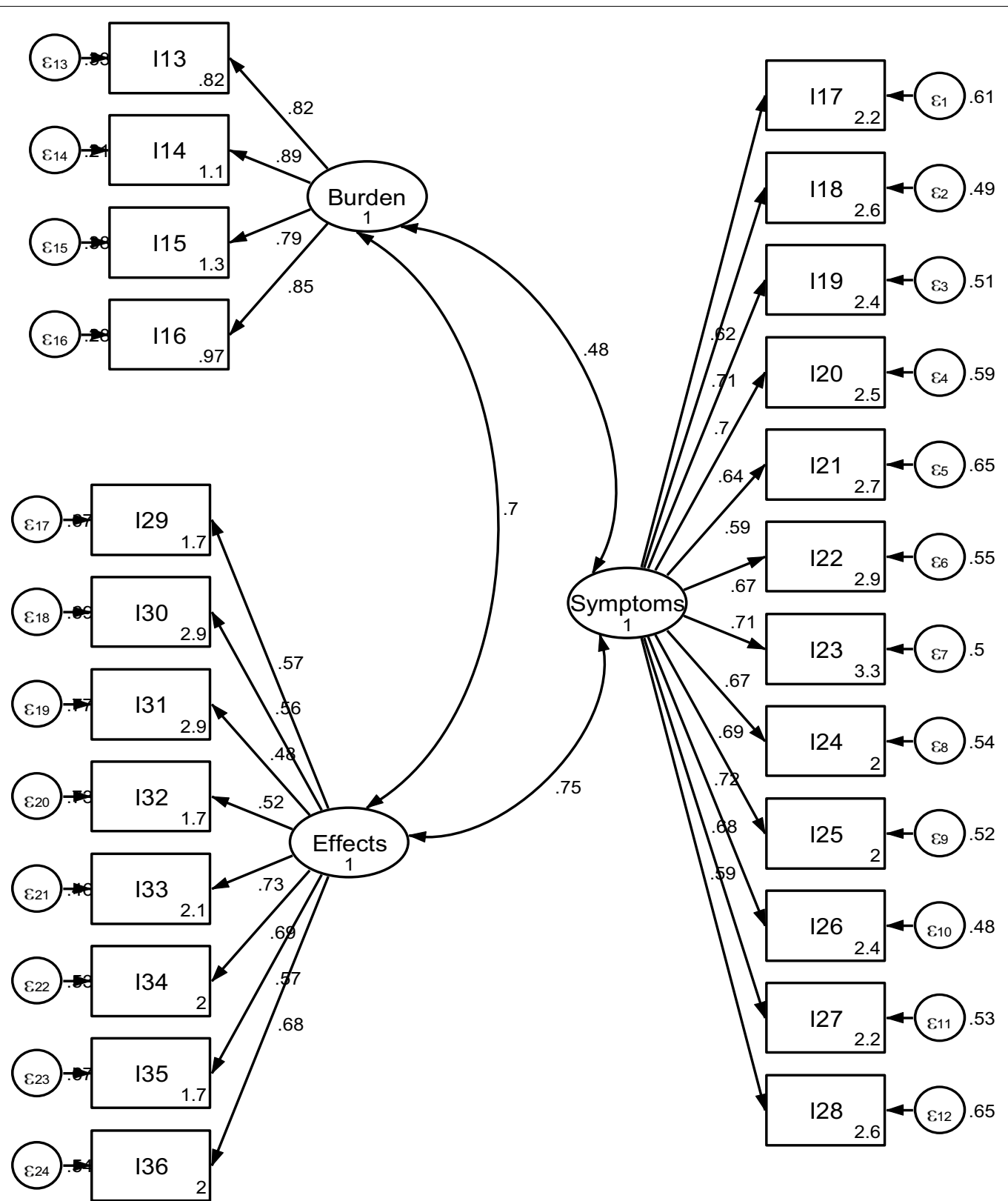

Fig. 2 A three-factor model for the disease-targeted scales obtained from confirmatory factor analysis among hemodialysis patients in Addis Ababa, Ethiopia, 2021

Table 3 Correlation between the domains of the Amharic version of the KDQOL-36 and the EQ-5D-5L and the VAS among hemodialysis patients in Addis Ababa, Ethiopia, 2021 ( $n=292)$

\begin{tabular}{llll}
\hline Domains & No. of items & $\begin{array}{l}\text { VAS correlation }(\mathbf{r}) \text { with } \boldsymbol{P} \\
\text { value }<\mathbf{0 . 0 0 0 1}\end{array}$ & $\begin{array}{l}\text { EQ-5D-5L correlation }(\mathbf{r}) \\
\text { with } \boldsymbol{P} \text { value }<\mathbf{0 . 0 0 0 1}\end{array}$ \\
\hline $\begin{array}{l}\text { Kidney disease targeted scales } \\
\text { Symptoms/problems list }\end{array}$ & 12 & 0.585 & 0.683 \\
Effects of kidney disease & 8 & 0.694 & 0.803 \\
Burden of kidney disease & 4 & 0.548 & 0.603 \\
\hline
\end{tabular}


Table 4 Differences on scale scores of the KDQOL-36 among hemodialysis patients in Addis Ababa, Ethiopia, 2021

\begin{tabular}{|c|c|c|c|c|c|}
\hline \multirow[t]{2}{*}{ Variables } & \multicolumn{5}{|c|}{ KDQOL-36 sub scales (mean, SD) } \\
\hline & Symptoms/problems list & Effects of kidney disease & Burden of kidney disease & SF-12 PCS & SF-12 MCS \\
\hline \multicolumn{6}{|c|}{ Diagnosis of diabetes } \\
\hline Yes (103) & 73.2 & 50.7 & 28.1 & 33.9 & 35.5 \\
\hline No (188) & 76.1 & 56.8 & 29.8 & 36.3 & 40.6 \\
\hline$P$ value & 0.144 & $0.015^{*}$ & 0.566 & $0.024^{*}$ & $0.006^{*}$ \\
\hline
\end{tabular}

*Statistically significant

that the scales can accurately measure the concept by capturing the deterioration or improvement in the course of the disease along with hemodialysis therapy.

All correlation coefficients in the corrected itemtotal correlation testing of the Amharic version of the KDQOL-36 were above 0.4 confirming construct validity of the Amharic version instrument. In line with the previous study in Singapore [23], the United States [42], China [44] and Malaysia [45], our data fit the three factor structure (symptoms/ problems list, burden of kidney disease and effects of kidney disease on kidney life). For the 12-item health survey, we found that a two factor structure (PCS and MCS) as we had hypothesized based on the SF-12 item health survey construction [27]. The factor loadings of all items in the disease-targeted scales and SF-12 health survey exceeded 0.4.

The correlations of the three kidney disease targeted scales with the EQ-5D-5L and EQ-VAS were all in the expected direction and the coefficients were of large magnitude supporting convergent validity of these scales. This finding was comparable with results from previous studies [20,45]. The Amharic version of the KDQOL-36 established evidence of known group validity as the scale scores were able to discriminate between subgroups of patients in relation to diabetes status. In this study, patients with diabetes had a worse quality of life than those without diabetes as expected and the reason could be complications resulted from the disease. This finding was supported by other recent studies evaluating the quality of life of ESRD patients [38, 39, $42,46]$.

In our study, the three kidney disease targeted scales showed good internal consistency (Cronbach's alpha $>0.8)$ in accordance with previous studies conducted in China [44], Malaysia [45], Thailand [20], Korea [47] and the United States [22, 42]. Similarly, the generic part of the instrument showed good internal reliability, which was comparable to previous studies in Malaysia [45], Iran [48], India [49] and Singapore [23]. At two-weeks test-retest, the ICC value ranged 0.090-0.961 for all the five scales, which was consistent with previous studies $[20,49,50]$. Thus, the Cronbach's alpha and ICC values suggested that the Amharic version of KDQOL-36 instrument is reliable.

\section{Strengths and limitations}

This study has several strengths. First, with a large sample (response rate 96\%) including patients from government as well as private hospitals, our sample was representative of the population undergoing hemodialysis in Addis Ababa, Ethiopia. Second, sample size of approximately 300 patients enabled rigorous statistical analyses to evaluate validity (construct and knowngroups validity). There are also a few limitations to be considered when concluding our results. Amharic is the most commonly used language in the country. Still, two patients were excluded as they did not speak or understand Amharic, and if they represent a subgroup that may perceive the items of the questionnaire in a different way is not known. The study collected data by face-toface interviews though self-administration, a procedure commonly practiced in administering the KDQOL-36 instrument. We choose this mode of administration as considerably large proportion of the population in Ethiopia cannot read and write and participants in pilot interviews expressed that they preferred to be interviewed in front of instead of filling out the questionnaire by themselves. It should also be noted that a higher proportion of the study participants was well educated compared to the population in the country as a whole. However, this reflects the actual population receiving hemodialysis due to kidney disease and not to be considered a selection bias. Additionally, despite the fact that we recruited 292 patients, the test-retest analysis was based on a smaller convenient portion of this group (50 patients). This could possibly inject a selection bias in to our test-retest analysis and skew the results. However, when compared to the rest of the cohort, it exhibited no significant differences in demographic variables. 


\section{Conclusion}

The KDQOL-36 in the Amharic language appears to be valid and reliable for measuring HRQOL of Ethiopian patients with end stage renal disease undergoing hemodialysis. The measure is recommended for use in clinical research in Ethiopia.

\section{Abbreviations}

CKD: Chronic kidney disease; CFA: Confirmatory factor analysis; EQ-VAS: European quality of life visual analog scale; ESRD: End stage renal disease; HRQOL: Health-related quality of life; ICC: Intra-class correlation; KDQOL-36: Kidney disease quality of life-36; MCS: Mental component summary; PCS: Physical component summary; SF-12: Short form-12; QOL: Quality of life.

\section{Supplementary Information}

The online version contains supplementary material available at https://doi. org/10.1186/s12955-022-01932-y.

Additional file 1: A re-specified two-factor model for the SF-12 PCS \& MCS scales from confirmatory factor analysis among hemodialysis patients in Addis Ababa, Ethiopia, 2021.

Additional file 2: A re-specified three-factor model for the diseasetargeted scales obtained from confirmatory factor analysis among hemodialysis patients in Addis Ababa, Ethiopia, 2021.

\section{Authors' information}

Mignote Hailu Gebrie is assistant Professor at the School of Nursing, College of Medicine and Health Sciences, University of Gondar, Ethiopia. She has a Bachelor of Science in Nursing (BSN) and MSN in Adult Health Nursing.

Hussen Mekonnen, assistant professor of public health, College of Health Sciences, School of Nursing \& Midwifery, Department of Nursing, Addis Ababa, Ethiopia.

Workagegnehu Hailu, an assistant professor in the department of Internal Medicine, University of Gondar, Ethiopia. He is an internist and nephrologist with over 10 years of experience in, research and clinical practice.

Helena Lindgren holds a position as senior lecturer (Associate professor) and Head of Division for Reproductive Health at Karolinska Institute, Sweden. She is also Visiting Professor at University of Gondar, Ethiopia.

Lena Wettergren, Professor at Uppsala University, Department of Public Health and Caring Sciences and is associated with the Karolinska Institutet, Sweden. She is also Visiting Professor at University of Gondar, Ethiopia.

\section{Acknowledgements}

Our heartfelt gratitude goes to University of Gondar for financial support. The authors would like to thank the respective hospitals and study participants who chose to participate in this study and to Rahawa Yousuf at the University of Gondar for editorial assistance with this manuscript.

\section{Authors' contributions}

$\mathrm{MH}$ together with LW conceived and planned the study. MH is the principal investigator of the project and led the translation process including cognitive interviewing, and the data collection for the psychometric evaluation. $\mathrm{MH}$ also performed the statistical analyses and wrote the original draft of the manuscript. LW, HL, HM and WH participated in the translational/adaptation phase, the data analysis and revised subsequent drafts of the manuscript. All authors read and approved the final manuscript.

\section{Funding}

The authors received no funding.

\section{Availability of data and materials}

The datasets generated and/or analyzed during the current study are available from the corresponding author on reasonable request.

\section{Declarations}

\section{Ethics approval and consent to participate}

Ethical approval was obtained before the initiation of the study from Institutional Review Board of University of Gondar and City Government of Addis Ababa Health Bureau, in a letter with a reference number V/P/ $\mathrm{RCS} / 05 / 2271 / 2020$ and A/A/H/5676/227, respectively. Permission was obtained from each hospital administrative body. Written informed consent was collected from all participants. All potential participants were informed about the purpose, method and expected benefit of the study. The participants were informed that there were no financial benefits for participating in the research, no potential harms that impact on their social status. They have also provided with the information regarding their full right to refuse from participating in this research without any effects on existing or future health care services. Confidentiality was maintained by keeping anonymity and presenting the data only on a group level.

\section{Consent for publication}

Not applicable.

\section{Competing interests}

The authors declare that they have no competing interests.

\section{Author details}

${ }^{1}$ College of Medicine and Health Sciences, School of Nursing, University of Gondar, Gondar, Ethiopia. ${ }^{2}$ College of Health Sciences, School of Nursing \& Midwifery, Department of Nursing, Addis Ababa University, Addis Ababa, Ethiopia. ${ }^{3}$ College of Medicine and Health Sciences, School of Medicine, Department of Internal Medicine, University of Gondar, Gondar, Ethiopia. ${ }^{4}$ Department of Women's and Children's Health, Division of Reproductive Health, Karolinska Institutet, Solna, Sweden. ${ }^{5}$ Department of Public Health and Caring Sciences, Uppsala University, Uppsala, Sweden.

Received: 12 November 2021 Accepted: 26 January 2022

Published online: 10 February 2022

\section{References}

1. Liyanage T, Ninomiya T, Jha V, Neal B, Patrice HM, Okpechi I, et al. Worldwide access to treatment for end-stage kidney disease: a systematic review. Lancet. 2015;385(9981):1975-82. https://doi.org/10.1016/S01406736(14)61601-9.

2. Mushi L, Marschall P, Fleßa S. The cost of dialysis in low and middleincome countries : a systematic review. BMC Health Serv Res. 2015. https://doi.org/10.1186/s12913-015-1166-8.

3. Halle MP, Takongue C, Kengne AP, Kaze FF, Ngu KB. Epidemiological profile of patients with end stage renal disease in a referral hospital in Cameroon. BMC Nephrol. 2015;16:1-18.

4. Moosa MR, Meyers AM, Gottlich E, Naicker S. An effective approach to chronic kidney disease in South Africa: in practice-healthcare delivery. South Afr Med J. 2016;106(2):156-9.

5. Bikbov B, Purcell CA, Levey AS, Smith M, Abdoli A, Abebe M, et al. Global, regional, and national burden of chronic kidney disease, 1990-2017: a systematic analysis for the Global Burden of Disease Study 2017. Lancet. 2020;395(10225):709-33.

6. National Kidney Foundation. K/DOQI Clinical practice guidelines for chronic kidney disease: evaluation, clasification and stratification. Vol. 39, Am J Kidney Dis. 2002. 1-266 p. www.kdoqi.org

7. Stevens P, O'Donoghue D, Lusignan S De. Chronic Kidney Disease (Ckd) Management in General Practice. Kidney Heal Aust [Internet]. 2015;15, 21, 22, 23. http://kidney.org.au/cms_uploads/docs/ckd-management-in-gphandbook-3rd-edition.pdf 
8. Rodger RSC. Approach to the management of end-stage renal disease. Clin Med (Northfield II) [Internet]. 2012;12(5):472-5. http://www.clinmed. rcpjournal.org/content/12/5/472.full

9. Trillini M, Perico N, Remuzzi G. Epidemiology of end-stage renal failure: the burden of kidney diseases to global health. Kidney Transpl Bioeng Regen Kidney Transpl Regen Med Era Elsevier Inc;; 2017. https://doi.org/ 10.1016/B978-0-12-801734-0.00001-1

10. Fiseha T. Prevalence of chronic kidney disease and associated risk factors among diabetic patients in Southern Ethiopia. Americfile///C/Users/ Admin/Desktop/Camera/CKD Etiol J Heal Res [Internet]. 2014;2(4):216. http://www.sciencepublishinggroup.com/journal/paperinfo.aspx?journal id=656\&doi=https://doi.org/10.11648/j.ajhr.20140204.28

11. Costa FG, Coutinho M da P de L, Costa FG, Coutinho M da P de L. Hemodialysis and depression: social representation of patients. Psicol em Estud [Internet]. 2014;19(4):657-67. http://www.scielo.br/scielo.php?script=sci_ arttext\&pid=S1413-73722014000400657\&lng =pt\&nrm=iso\&tlng=en

12. Barbosa JBN, Moura ECSC, Lira CLOB MP. Quality of life and duration of hemodialysis in patients with chronic kidney disease (CKD): a crosssectional study. 2017;30(4):781-8.

13. Ghadam MS, Poorgholami F, Badiyepeymaie Jahromi Z, Parandavar N, Kalani N, Rahmanian E. Effect of self-care education by face-to-face method on the quality of life in hemodialysis patients (relying on ferrans and powers questionnaire). Glob J Health Sci [Internet]. 2015;8(6):121. http://www.ccsenet.org/journal/index.php/gjhs/article/view/54270

14. Abdel-Kader K, Unruh ML, Weisbord SD. Symptom burden, depression, and quality of life in chronic and end-stage kidney disease. Clin J Am Soc Nephrol. 2009:4(6):1057-64.

15. Ayoub AM, Hijjazi KH. Original article quality of life in dialysis patients from the United Arab Emirates. J Family Commun Med. 2013;20(2):106-13.

16. Guyatt GH, Bombardier C \& TP. Measuring disease-specific quality of life in clinical trials. CMAJ. 1986;134.

17. Bass EB, Jenckes MW, Fink NE, Cagney KA, Wu AW, Sadler JH, et al. Use of focus groups to about dialysis identify concerns. Med Decis Mak. 1999;19:287-95.

18. Edgell ET, Stephen I, Coons J, Carter WB, Kallich JD, Mapes D, et al. A review of health-related quality-of-life measures used in end-stage renal disease. Clin Therapeut. 1996;18(5):887-938.

19. Guyatt GH, Feeny DH, Patrick DL. Measuring health-related quality of life. Ann Internal Med. 1993;18:622-9.

20. Thaweethamcharoen T, Srimongkol W, Noparatayaporn P, Jariyayothin P, Sukthinthai N, Aiyasanon N, et al. Validity and reliability of KDQOL-36 in thai kidney disease patient. Value Heal Reg Issues. 2013;2(1):98-102. https://doi.org/10.1016/j.vhri.2013.02.011.

21. Chow SKY, Tam BML. Is the kidney disease quality of life-36 (KDQOL36) a valid instrument for Chinese dialysis patients? BMC Nephrol. 2014;15(1):1-7.

22. Ricardo AC, Hacker E, Lora CM, Ackerson L, Desalvo KB, Go A, et al. Validation of the kidney disease quality of life short Form 36 (KDQOL-36TM) US Spanish and English Versions in a cohort of Hispanics with chronic kidney disease. 2013;23.

23. Yang F, Wang VW, Joshi VD, Lau TWL, Luo N. Validation of the english version of the kidney disease quality of life questionnaire (KDQOL-36) in haemodialysis patients in Singapore. Patient. 2013;6(2):135-41.

24. Hays ID, Kallich JD. Development of the Kidney Disease Quality of Life ( KDQOLTM ) Instrument. 1994;3:329-38.

25. Kidney Disease and Quality of Life ${ }^{\mathrm{TM}}\left(\mathrm{KDQOL}^{\mathrm{TM}}-36\right)$, English Version 1. RAND Univ Arizona. 2000;

26. Kalantar-Zadeh $K$ \& Unruh $M$. Health related quality of life in patients with chronic kidney disease Kamyar. Int Urol Nephrol. 2005;37(2).

27. Ware JE, Kosinski M, Keller SD. A 12-item short-form health survey: construction of scales and preliminary tests of reliability and validity. Med Care. 1996;34(3):220-33.

28. Ware JE KM\& KS. SF-12: How to score the SF-12 physical and mental health summary scales. Heal Institute, New Engalnd Med center, Bost. 1995; second edi.

29. Hays RD, Kallich JD, Mapes DL, Coons SJ, Amin N CW\& KC. Kidney Diseaase Quality of Life Short Form (KDQOL-SF), version 1.3: A Manual for Use and Scoring. 1997.

30. Reenen M van, Janssen B, Stolk E, Boye KS, Herdman M, KennedyMartin M, et al. EQ-5D User Guide: BAsic information on how to use the
EQ-5D-5L instrument. EueoQol Res Found [Internet]. 2019;36. https:// eurogol.org/publications/user-guides/

31. Herdman M, Gudex C, Lloyd A, Janssen M, Kind P, Parkin D, et al. Development and preliminary testing of the new five-level version of EQ-5D (EQ-5D-5L). Qual Life Res. 2011;20(10):1727-36.

32. Stata Corp. StataSE. College Station, TX: Stata Corp LP.; 2017.

33. Ware JE, Gandek B. Methods for testing data quality, scaling assumptions, and reliability: The IQOLA Project approach. J Clin Epidemiol. 1998:51(11):945-52.

34. Byrne BM. Structural Equation Modeling with AMOS. second edi. New York London; 2010.

35. Schermelleh-Engel $\mathrm{K}$, Moosbrugger $\mathrm{H}$, Müller $\mathrm{H}$. Evaluating the fit of structural equation models: tests of significance and descriptive goodness-of-fit measures. MPR-online. 2003;8(May):23-74.

36. Kline RB. TXTBK Principles and practices of structural equation modelling Ed. $4{ }^{* * *}$. Methodology in the social sciences. 2015. 1-554 p.

37. Cohen J. Statistical power analysis for the behavioral sciences. 2 nd ed. Hillsdale, NJ: L. Erlbaum Associates.; 1988. 567 p.

38. Yusop NB, Mun CY, Shariff ZM, Huat C. Factors associated with quality of life among hemodialysis patients in Malaysia. PLoS One. 2013;8(12):1-11.

39. Rawat KJ, Joshi KS, Arora RD. Quality of life in patients on hemodialysis: A quasi-experiment with review of literature. Int J Med Sci Public Health. 2017;6(4):786-91.

40. Jensen MP. Questionnaire validation : a brief guide for readers of the research literature. 2003;345-52.

41. KoO T, Li M. A guideline of selecting and reporting intraclass correlation coefficients for reliability research. J Chiropr Med. 2016. https://doi.org/ 10.1016/j.jcm.2016.02.012

42. Peipert JD, Bentler PM, Klicko K, Hays RD. Psychometric properties of the kidney disease quality of life 36 -item short-form survey (KDQOL-36) in the United States. Am J Kidney Dis. 2018;71(4):461-8. https://doi.org/10. 1053/j.ajkd.2017.07.020.

43. Arafat SMY, Chowdhury R. Cross-cultural adaptation and psychometric validation of research instruments: a methodological review. J Behav Health. 2016;5(3):129-36.

44. Chen JY, Choi EPH, Wan EYF, Chan AKC, Tsang JPY, Chan KHY, et al. Validation of the disease-specific components of the kidney disease quality of Life-36 (KDQOL-36) in Chinese patients undergoing maintenance dialysis. PLOS ONE. 2016;11(5):1-13.

45. Goh KKK, Lai PSM, Lim SK. Cross cultural adaptation and validation of the Malay Kidney Disease Quality of Life (KDQOL-36 ${ }^{\mathrm{TM}}$ ). BMC Nephrol. 2019;20(1):1-9.

46. Kamal NN, Kamel EG, Eldessouki KH, Ahmed MG. Health-related quality of life among hemodialysis patients at El-Minia University Hospital. Egypt J Public Heal. 2013;21(2):193-200.

47. Park HJ, Kim S, Yong JS, Han SS, Yang DH, Meguro M, et al. Reliability and validity of the Korean version of kidney disease quality of life instrument (KDQOL-SF ${ }^{\text {TM }}$ ). Tohoku J Exp Med. 2007;211(4):321-9.

48. Montazeri A, Vahdaninia M, Mousavi SJ, Omidvari S. The Iranian version of 12-item short form health survey (SF-12): Factor stucture, internal consistency and construct validity. BMC Public Health. 2009;9:1-10.

49. Mateti UV, Nagappa AN, Attur RP, Nagaraju SP, Mayya SS, Balkrishnan R. Cross-cultural adaptation, validation and reliability of the South Indian (Kannada) version of the Kidney Disease and Quality of Life (KDQOL-36) instrument. Saudi J Kidney Dis Transpl. 2015;26(6):1246.

50. Tao $X$, Chow SKY, Wong FKY. Determining the validity and reliability of the Chinese version of the Kidney Disease Quality of Life Questionnaire $\left(\right.$ KDQOL-36 $\left.{ }^{\mathrm{TM}}\right)$. BMC Nephrol. 2014;15(1):1-9.

\section{Publisher's Note}

Springer Nature remains neutral with regard to jurisdictional claims in published maps and institutional affiliations. 